\title{
A formação intelectual de Sérgio Buarque de Holanda
}

\author{
Rodrigo Ruiz Sanches ${ }^{1}$ \\ Professor do Depto de Ciências Sociais \\ Faculdade Barretos \\ dr.rodrigoruiz@gmail.com
}

Como citar este artigo: SANCHES, R. R “A formação intelectual de Sérgio Buarque de Holanda”, n8, pp. 125-149. 2019. Disponível em < http://revistas.usp.br/revistaintelligere>. Acesso em dd/mm/aaaa.

Resumo: Neste artigo, discutimos a formação humana e acadêmica de Sérgio Buarque de Holanda. Percebemos que o contato com a crítica literária e com o modernismo marcou o jovem historiador de várias maneiras, pois revelou a aguda crítica e a escolha pela escrita leve, mas profunda, em que transparece toda sua erudição, lapidada, gradativamente, com os anos de experiência. É nesse momento que se formou o escritor Sérgio Buarque de Holanda, que depois transformou-se em historiador (aliás, ele nunca deixou de ser as duas coisas). A ideia central deste artigo é revelar a gênese do intelectual independente que foi Sérgio Buarque de Holanda, presente desde seus primeiros escritos, mas, sobretudo, em seus discursos e ações. $\mathrm{O}$ recorte compreende as décadas de 20,30, 40 e 50 do século XX. Entendemos que esse período corresponde aos anos em que Sérgio iniciou sua vida profissional, atuou como crítico literário e optou pela profissão de historiador.

Palavras-chave: Sérgio Buarque de Holanda, Modernismo, Intelectuais e Estado.

\section{Sérgio Buarque de Holanda's intellectual formation}

Abstract: In this article we discuss Sérgio Buarque de Holanda's human and academic formation. We observe that the contact with the literary criticism and the modernism marked the young historian in many ways as it show the acute and critical choice by easy but deep, in which all his erudition appears to be gradually improved with years of experience. It is at moment that, Sérgio Buarque de Holanda, really became a writer and later became a historian (indeed, he never ceased to be both). The main idea of

${ }^{1}$ Bacharel (1996) e Licenciado (1997) em Ciências Sociais pela Unesp/Araraquara. Mestrado (2001) em Sociologia pela Unesp/Araraquara. Doutorado (2007) em Sociologia pela Unesp/Araraquara. Pós-Doc na UFSCar (2013). Professor universitário desde 1998. Docente da Faculdade Barretos, onde é Diretor de Extensão e Coordenador da CPA. 
this paper is to reveal the genesis of the independent intellectual that Sérgio Buarque de Holanda was, present since the begining of his writings, but above all, present in his speeches and actions. The delimitation of the theme is from the 20's, 30's, 40's and 50 's of the twentieth century. We believe that this period corresponds to the years when Sergio began his professional life, served as literary critic and choose to be a historian.

Keywords: Sérgio Buarque de Holanda, Modernism, Intellectuals and the State.

Nas palavras de Sérgio Buarque de Holanda: "Eu me formei, como várias pessoas, em várias épocas e em diversos lugares, não apenas em instituições educacionais e encontros formais, mas também através de amizades - muito importante para nós brasileiros". (Graham, 1987).

Estudar um autor é uma das tarefas mais difíceis para um pesquisador. Ele deve mergulhar fundo nas obras produzidas e publicadas; situá-las no tempo e no espaço, procurando contextualizá-las; encontrar as principais referências, nem sempre explícitas; daí, lê-las e relê-las várias vezes, quase sempre surpreendendo-se com os "achados"; desvendar os principais interlocutores do autor ${ }^{2}$; descobrir quais obras literárias e científicas ele leu; dimensionar o impacto da sua obra na época, o seu espaço na história e sua atualidade. Juntamente com isso, deve-se compreender o ser humano por trás do escritor; sua vida, sua trajetória, sua família e amigos. Longe de ser uma condição sine qua non, a relação autor/obra revela mais do que esconde. Helenice Rodrigues Silva (2002, p.51) afirma que a vida pessoal é importante objeto de estudo do pesquisador: "Dentro da perspectiva de uma história intelectual, as experiências de vida, ou seja, a trajetória de um autor permite traçar pistas para uma melhor compreensão das condições de elaboração de uma obra".

\footnotetext{
${ }^{2}$ Karl Mannheim enfatiza a "natureza coletiva da criação intelectual", que é um aspecto de relevância, pois intercepta na mensagem de uma obra ou em seu estilo o resultado do pensamento de um ou mais grupos sociais sobre a realidade vivida. Do mesmo modo, Lefort (1992, p.147) diz que, se quisermos conhecer as intenções de um escritor, parece bom indagar quais são seus interlocutores privilegiados, quais são as opiniões que tem em mira, quais são as circunstâncias que instigam seu desejo de falar. Questões, por certo, observemos de passagem, às quais não basta responder, supondo que podemos respondê-las, para dar conta de seu pensamento, pois é igualmente verdadeiro que ele não escreve para alguém, que se liga a um leitor sem identidade definida, leitor cujo lugar será ocupado por desconhecidos, num futuro que ele não pode imaginar; e ainda é verdade que ele aufere das circunstâncias um poder de pensar que transcende a contingência da situação em que se encontra.
} 


\section{Os anos 1920 com os modernistas}

$\mathrm{Na}$ década de 1920, inicia-se o processo da liquidação da bele époque, a crise do liberalismo e da própria democracia, o pânico da expansão comunista e a ascensão do totalitarismo, com o fascismo triunfante e a primeira vitória do nazismo nas eleições alemãs de 1929. No Brasil, há um fortalecimento das idéias conservadoras, que encontram na vanguarda modernista, sobretudo a dos grupos do Pau Brasil e da Antropofagia, um vigoroso sopro contestatório. (Barbosa, 1988).

Os anos 20, para Sérgio Buarque de Holanda, foram anos de formação não só intelectual, mas de construção de amizades que duraram por toda sua vida. Sérgio teve muitos amigos. A rede de sociabilidade dele era enorme. Maria Amélia Alvim, viúva, relata ${ }^{3}$ ainda, as noitadas no Rio com Donga, Pixinguinha, Araci de Almeida, Noel Rosa e Ismael Silva. Na Rua Buri, em São Paulo, recebia os amigos Vinícius de Moraes, Antonio Candido, Caio Prado Júnior, Manuel Bandeira, Prudente de Morais Neto, Carybé, Paulo Vanzolini, Florestan Fernandes, Clóvis Graciano, Dorival Caymmi.

Esse período é marcado pelo surgimento do movimento modernista. O modernismo foi, sem sombra de dúvidas, uma das mais importantes correntes do pensamento brasileiro. Como toda nova corrente, ela rompe com o passado, trazendo nova forma de pensar e escrever a literatura. Mas não foi só isso, encontramos a idéia modernista manifestada na pintura, arquitetura e nos ensaios voltados para a explicação da realidade brasileira. Os modernistas, oriundos em sua maioria de famílias abastadas da oligarquia e, portanto, próximos aos círculos intelectualizados, estavam vinculadas às vanguardas européias; isto permitiu a eles assumir um papel de inovadores culturais e estéticos no campo literário local, num processo chamado por Sérgio Miceli (1979) de "substituição de importação" de bens culturais. Tais escritores se diferenciam entre si não tanto pelo volume de "capital econômico e escolar", como conceitua esse autor, mas pela proximidade relativa de suas famílias em

\footnotetext{
${ }^{3}$ Em uma biografia chamada "Apontamentos para a cronologia de Sérgio", publicada no site www.unicamp.br/sbh, em 2002.
} 
relação à fração intelectual e política da classe dirigente e, por conseguinte, pelo grau de conservação ou de dilapidação de seu capital de relações sociais.

Com o movimento modernista, a literatura ganhou inovações formais e temáticas. Isso ocorreu em dois níveis: quanto à fisionomia da obra e quanto à rejeição dos velhos padrões. Candido (1989) afirma que, na década de 30, o inconformismo e o anticonvencionalismo tornaram-se um direito, não uma transgressão. Isso beneficiou a todos os escritores desse período, pois podiam agora ter uma liberdade maior em suas criações.

Conforme anotou Avelino Filho (1987, p.35), o modernismo coloca os grupos populares na ordem do dia como componentes da sociedade e da nação:

Portanto, o movimento modernista não pode ser resumido a uma crítica da cultura bacharelesca: ele é também uma tentativa de redescoberta do Brasil, da ambigüidade e riqueza de suas contradições, bem como da impossibilidade de sua negação. Projeto estético e projeto ideológico andavam juntos.

A história intelectual da geração anterior ${ }^{4}$ foi marcada negativamente pela dependência perante o Império e o isolamento no início do século XX, mas tentou reatar o prestígio das elites de Estado, o qual caracterizava todo o período do Império. Essa condição de dependência consistira em mecenato, patronagem e honrarias, comportando a outorga de empregos públicos aos escritores, mas também seu enclausuramento no círculo das elites sociais. O isolamento deu-se pelo desprezo pela organização de um Estado baseado na "política dos governadores" e em favor das oligarquias regionais. A geração de 20 foi herdeira dessa postura ao reclamar do Estado uma verdadeira autoridade, tomou como ponto pacífico o fato de que sua missão era, primeiro, política. (Pécault, 1990).

Os escritores latino-americanos são produtores de bens culturais para minorias. Antonio Candido, citando o poema de Castro Alves O livro e a América, afirma que os intelectuais construíram uma visão igualmente

\footnotetext{
${ }^{4}$ Simplesmente chamados de "pré-modernistas" pelos modernistas (detentores de autoridade intelectual na década de 20): "seriam os epígonos das escolas dominantes no final do século XIX, os deserdados das grandes causas políticas - como, por exemplo, a Independência para os românticos, o abolicionismo e o movimento republicano para a geração naturalista -, os importadores otimistas das escolas européias periféricas ao simbolismo, os descristianizados. (Miceli, 200, p.16).
} 
deformada da sua posição em face da incultura dominante. Na verdade, os intelectuais "flutuavam", pois viviam em eternas "influências estrangeiras" e numa "dependência cultural". "A consciência do subdesenvolvimento é posterior à Segunda Guerra Mundial e manifestou-se claramente a partir de 1950". (Candido, 1989, p. 142).

A partir de 1950, sentimos que a dependência se encaminha para uma interdependência cultural. Essa "alienação cultural” fazia com que os escritores escrevessem para fora, para o exterior, dissociando-se, muitas vezes, de sua terra. Daí o excessivo uso da língua estrangeira na redação das obras. "E assim vemos que analfabetismo e requinte, cosmopolitismo e regionalismo, podem ter raízes misturadas no solo da incultura e do esforço para superá-la". (Candido, 1989, p. 149).

Nosso País, segundo Candido, era o exemplo claro de certo "provincianismo cultural", onde poucos homens "semicultos", escreviam para a grande massa analfabeta. De fato, a originalidade não foi uma característica de nossa literatura. Candido chama de "fenômeno da ambivalência", que estimula a cópia servil, imitação de estilos, temas e atitudes e usos literários. Mesmo o regionalismo, Candido considera envelhecido, não é mais forma privilegiada de expressão literária nacional.

A importação de idéias não é uma tese nova. Embora Roberto Schwarz tenha-se tornado famoso com o texto As idéias fora do lugar, Sérgio Buarque de Holanda havia anunciado essa faceta dos escritos brasileiros já em Raízes do Brasil.

Para Nemi (2003, p.134-5),

\footnotetext{
A experiência intelectual brasileira desenvolveu-se em meio a esta dialética entre o universal e o local onde se forma o texto literário, mas não se completa a nação. O que é ambíguo no processo formativo nacional, aquela dialética entre o universal e o local, é elemento formativo da experiência intelectual.
}

Segundo Miceli (2001), nessa fase, desenvolveram-se as condições sociais favoráveis à profissionalização do trabalho intelectual, sobretudo em sua forma literária, e à constituição de um campo intelectual relativamente autônomo, em conseqüência das exigências postas pela diferenciação e 
sofisticação do trabalho de dominação. Em termos concretos, finaliza Miceli, toda a vida intelectual era dominada pela grande imprensa, que constituía a principal instância de produção cultural da época e fornecia a maioria das gratificações e posições intelectuais. Mesmo porque os intelectuais não dispunham de um princípio de identidade em um campo autônomo que remetesse a vínculos institucionais, como é o caso das universidades. Não havia no Brasil uma tradição universitária, que só viria a se constituir na década de 30. Não é sem razão que a atividade profissional de Sérgio Buarque de Holanda tenha-se concentrado no exercício de crítica literária publicada em diversos jornais.

Contemporâneo dos modernistas, Sérgio foi amigo de Mário de Andrade, e de outros modernistas. Embora não tenha participado diretamente da Semana de Arte Moderna ${ }^{5}$, realizada em São Paulo no ano de 1922, ele torna-se, no mesmo ano, representante da Revista Klaxon $-1^{2}$ revista do movimento. Contribuiu para sua divulgação através de publicações de ensaios e críticas literárias nos jornais e revistas da época:

\footnotetext{
Modernista, tomava atitudes críticas com relação às noções de legados, tradições, nação e raça; rejeitava providencialismos e procurava caminhos para libertar a História de finalidades necessárias. Revoltava-se contra determinismos cientificistas e materialistas, racistas, climáticos e biológicos, causalidades mecanicistas e leis abstratas pareciam mais apropriadas às ciências naturais do que à explicação de fenômenos históricos. (Dias, 1985, p.9).
}

A ruptura com o modernismo, presente no artigo "O lado oposto e outros lados" ${ }^{\prime 6}$, (Barbosa, 1989, p.85), reflete uma mudança de comportamento frente ao academicismo presente no movimento modernista, o que levou ao engessamento metodológico e à falta de liberdade de criação. Por isso ele decide "romper com todas as diplomacias nocivas, mandar pro diabo qualquer forma de hipocrisia, suprimir as políticas literárias e conquistar uma profunda sinceridade para com os outros e pra comigo mesmo". Para Sérgio Buarque de Holanda (1996, p.85), “a gente de hoje aboliu escandalosamente, graças a

\footnotetext{
${ }^{5}$ Sobre a influência do modernismo, ver Prado (1998).

6 "Os outros lados" pertence o grupo formado por Oswald de Andrade, "um dos sujeitos mais extraordinários do modernismo brasileiro", bem como Prudente de Moraes, neto, Couto de Barros e Antonio de Alcântara Machado.
} 
Deus, aquele ceticismo bocó, o idealismo impreciso e desajeitado, a poesia 'bibelô', a retórica vazia, todos os ídolos da nossa intelligentsia, e ainda não é muito que fez". Sérgio refere-se a Graça Aranha, Ronald de Carvalho, Renato Almeida, Tristão de Ataíde e Guilherme de Almeida, que "falam uma linguagem que a geração dos que vivem esqueceu há muito tempo". (Holanda, 1996, p.86). Estão situados "do outro lado", e "houve um tempo em que esses autores foram tudo quanto havia de bom na literatura brasileira. No ponto em que estamos hoje, eles não significam mais nada para nós [grifos do autor]". (Holanda, 1996a, p.86).

A crítica mais árdua que Sérgio Buarque de Holanda faz em relação a esses modernistas academizantes que idealizam, em suma, "a criação de uma elite de homens inteligentes e sábios, embora sem grande contato com a terra e com o povo [...], gente bem-intencionada e que esteja de qualquer modo à altura de nos impor uma hierarquia, uma ordem, uma experiência que estrangulem de vez esse nosso maldito estouvamento de povo moço e sem juízo ”. (Holanda, 1996, p.87). Esse tema é retomado em Raízes do Brasil quando Holanda critica a inteligência nacional calcada no bacharelismo dos fazedores de teorias ou dos importadores de soluções ou idéias vindos de fora, como foi o caso do liberalismo e do positivismo. Essa atitude já revela uma das características marcantes do intelectual independente que foi Sérgio Buarque de Holanda: o verdadeiro horror a qualquer forma de engessamento teórico que impede uma melhor compreensão dos fatos históricos.

Saturado de todos esses embates, Sérgio Buarque de Holanda só encontrou uma saída: aceitar o convite de seu amigo Vieira da Cunha para dirigir o jornal O Progresso, em Cachoeiro do Itapemirim, no Espírito Santo, em 1927 (ficou por lá por seis meses), onde ficou conhecido como Dr. Progresso. Manuel Bandeira relembra que quase Sérgio fica por lá definitivamente, não fosse o veto do governador no ato que o nomeava professor de História Universal e História do Brasil. "Benditos porres de Cachoeiro do Itapemirim!", ironizava Bandeira, feliz pela devolução de Sérgio em perfeito estado.

De volta ao Rio de Janeiro integra-se à redação de O Jornal. Em 1927, entrevista Luigi Pirandello e Blaise Cendrars. De fato, o interesse de Sérgio 
Buarque de Holanda pelo movimento Surrealista ${ }^{7}$ na França foi decisivo para a experiência criadora do historiador. Segundo Eulálio (1993, p.21), "tais investidas pioneiras no Brasil permanecem singulares pelo interesse estético e psicológico que encerram; aparentemente são as únicas de que se tem notícia em nosso meio até o final da Segunda Grande Guerra”.

O modernismo, ao que parece, não foi abraçado com tanta afeição por Sérgio Buarque de Holanda. No entanto, seu princípio de compreender o Brasil veio ao encontro de suas idéias. Independentemente de suas ressalvas, o modernismo possibilitou a realização de uma nova fase de nossa literatura, mais autêntica e mais livre em relação às idéias e temas estrangeiros, exatamente aquilo que Sérgio Buarque de Holanda sempre pregou e, a nosso ver, característica central do intelectual independente.

\section{Os anos 1930 e a relação entre intelectuais e Estado}

Nesse período, como observa Candido (1989), houve um “convívio íntimo" entre a literatura e as ideologias políticas e religiosas. Houve também uma admiração dos intelectuais, às vezes de modo explícito, pelas correntes comunistas e fascistas: "Muitas vezes o espiritualismo católico levou o Brasil dos anos 30 à simpatia pelas soluções políticas de direita, e mesmo fascistas, como foi o caso do Integralismo" (Candido, 1989, p.31). Por outro lado, ele observa que, neste período, também houve um grande interesse pelas correntes de esquerda, como, por exemplo, a Aliança Nacional Libertadora. Esse interesse pelos assuntos de esquerda está comprovado pelo aumento considerável de títulos publicados relacionados a temas como anarquismo, sindicalismo, marxismo, movimento operário, que aparecem nas livrarias, juntamente com traduções e a formação de uma corrente marxista brasileira, como é o caso de Caio Prado Jr.

Tratava-se de encontrar, pela reflexão histórica e sociológica, as causas ou origens do desajuste entre o Estado e a Sociedade, o "Brasil legal" e o "Brasil real". O debate em torno dessa questão é polarizado naquilo que ficou conhecido como "pensamento político autoritário"8 e "pensamento político

\footnotetext{
7 Ver Leonel (1984).

${ }^{8}$ Um estudo mais aprofundado sobre o "pensamento político autoritário" foi realizado por Lamounier (1977). Para o autor, o pensamento autoritário foi formado a partir da Primeira
} 
democrático". O ponto em comum dos representantes do pensamento autoritário é a descrença de uma solução, por vias democráticas, para o impasse "Estado e sociedade". A marca do pensamento autoritário está no fortalecimento e na intervenção do Estado, em detrimento da sociedade. Inversamente, a corrente democrática acreditava que não existia um impasse entre Estado e sociedade, mas estavam resolutos a superar nossos problemas por vias democráticas, através da ampliação da participação popular e das reformas institucionais.

O que percebemos nos anos 20 e 30, é a polarização dos intelectuais em torno dessas duas correntes. Notamos que tal debate vai além do mundo das idéias, havendo, sim, uma participação efetiva nos quadros burocráticos estatais.

Para Barbato Jr. (2004), os intelectuais nos anos 30 viviam uma confusão entre o transigir ou recusar a participação nas esferas do poder público. Segundo o ele, Capanema oferece aos intelectuais a possibilidade de realizar seus projetos.

República. São ensaios histórico-sociológicos que criticam o modelo constitucional de 1891, tendo em vista a ação política e a proposição de algum modelo alternativo de organização político-institucional. Os seus representantes mais notáveis são Alberto Torres, Oliveira Vianna, Azevedo Amaral e Francisco Campos. A marca dessa geração é, sem dúvida, expressa através do fortalecimento do poder político central. A tese de Lamounier é que tais autores, embora muito diferentes, tinham uma "ideologia autoritária" comum: "O conceito de 'ideologia de Estado’ pode ser visto como uma construção intelectual que sintetiza e dá direção prática a um clima de idéias e de aspirações políticas de grande relevância nas últimas décadas do século XIX e na primeira metade deste [XX]" (p.356). Para ele, o que é comum na bibliografia brasileira é atribuir sentido "ideológico" somente aos grupos de extrema direita e extrema esquerda, ou seja, somente a minorias fortemente intelectualizadas e possuidoras de um projeto explícito de mudança política. O conceito de "ideologia de Estado" de Lamounier pretende exatamente acentuar o contraste com a matriz ideológica à qual se opõe: o Mercado: "O fulcro da ideologia de Estado é, ao contrário, o intento de domesticar o Mercado, e particularmente o princípio de mercado atuante nas relações políticas”. (p. 358). Nacionalistas podem ter um pensamento "irrelevante, descolado do mundo real e com uma insuficiência conceitual e metodológica”, isso devido ao descrédito das idéias autoritárias. Apesar disso, Lamounier reconhece a importância desses autores para a história do pensamento político no Brasil: "O pensamento político do período deve ser entendido como a formação de um sistema ideológico orientado no sentido de conceituar e legitimar a autoridade do Estado como princípio tutelar da sociedade" (p.356). Essa importância também é verificada de três formas: pela importância que tais autores tiveram na difusão e na institucionalização das Ciências Sociais no Brasil; pela impulsão dada às elites culturais de uma corrente antiliberal; pela "prática política" ou "ação política" nas transformações institucionais verificadas após a Revolução de 1930. 
O escrito seminal sobre a relação entre intelectuais e Estado foi realizado por Sérgio Miceli (2001). Este texto travou um diálogo com todos os estudos sobre intelectuais nos últimos 25 anos. O texto apresenta, nas palavras do autor, "uma argumentação sociológica com tinturas culturalistas". Miceli adotou um modelo de argumentação capaz de compatibilizar condicionantes ligados às origens sociais com aqueles desencadeados pelas mudanças em curso no mercado de trabalho intelectual, uns e outros tomando feição e sentido no contexto político-institucional da época. Os três capítulos do livro cobriam os principais setores em expansão no mercado de trabalho em que concorriam os postulantes às carreiras intelectuais: partidos e instituições culturais a oligarquia paulista, frentes de mobilização político-ideológica de organizações integralistas, católicas e de esquerda, a indústria editorial impelida pelo surto do romance, o serviço público.

\begin{abstract}
O destino social desses intelectuais ia sendo moldado em meio às circunstâncias de suas orientações e representações de gênero, expostos às marcas neles instiladas por toda sorte de estigmas, às quais se acresciam as injunções de sua posição na linguagem, na fatria, em famílias de 'parentes pobres' da oligarquia, incentivados pelas oportunidades de aquisição de capital escolar e cultural, que dariam acesso preferencial àquelas posições profissionais conquistadas por força do cabedal de relações sociais. (Miceli, 2001, p. 373).
\end{abstract}

Os intelectuais pertencentes ao pensamento político autoritário são chamados por Miceli de "intelectuais reacionários", que possuem, na verdade, dupla condição: a de políticos profissionais e intelectuais. Com a derrota da oligarquia paulista em 1930 e em 1932, os membros do PRP passaram às fileiras dos movimentos radicais à direita e à esquerda, enquanto alguns de seus antigos companheiros foram cooptados para cargos de cúpula da administração pública federal. Enquanto isso, os membros do Partido Democrático tiveram a oportunidade de continuar prestando sua colaboração política à oligarquia. Aqueles que, por motivo da derrota da oligarquia na década de 30, foram alijados das carreiras políticas de maior prestígio, uniramse em torno de partidos ou organizações políticas "radicais" (como a Ação Integralista Brasileira) que pretendiam, por via autoritária, restaurar as relações de forças vigentes antes de 1930. Por estarem muito próximos ao partido, 
sendo até militantes, tais intelectuais não tinham a distância necessária para ver a realidade das transformações que acarretariam a derrota da oligarquia:

A maioria dos jovens intelectuais que se tornaram militantes nas organizações 'radicais' de direita durante a década de 30, eram bacharéis livres [intelectuais que não dispõem de quaisquer trunfos sociais senão a posse de um diploma superior e de uma competência em Ciências Sociais] e letrados que estavam desnorteados, carentes de apoio político e sem perspectiva de enquadramento profissional e ideológico. (Miceli, 1979, p.25).

Outros dois tipos de intelectuais destacados por Miceli são os educadores profissionais e os pensadores autoritários. Os primeiros foram as únicas categorias de intelectuais convocadas pela elite burocrática em virtude de sua competência e do saber que dispunham em suas respectivas áreas de atuação. Os autoritários, pertencentes a antigas famílias dirigentes, utilizavamse desses laços sociais para converterem seus pontos de vista em ortodoxia ideológica, aliados à ruptura com as doutrinas e modelos jurídicos então dominantes:

Os pensadores autoritários eram, na verdade, herdeiros que puderam tirar partido de uma correlação de forças extremamente favorável à produção de obras cujos reclamos reformistas coincidiam com os interesses de autopreservação da fração de classe a que pertenciam. (Miceli, 1979, p.31).

Incluem-se, nesta corrente, autores de trajetórias políticas díspares e provenientes de setores diferentes da classe dirigente. Publicistas são jovens pensadores que logravam ser os mentores intelectuais da classe dirigente. Os principais artífices eram Oliveira Vianna e Azevedo Amaral: "Falavam em nome da elite burocrática, na crença de que a organização do poder nas mãos do Estado viria substituir-se ao entrechoque de interesses privados, habilitando seus representantes a auscultar os reclamos do conjunto da sociedade". (Miceli, 1979, p.35).

Miceli destaca, ainda, a participação de pessoas oriundas dos grupos de esquerda, como alguns elementos da liderança anarquista. Como eles tinham experiência em comando de sindicatos e direção de órgão de representação, com a sua cooptação, tentava-se esvaziar seu poder contestatório. A contratação desses servidores fazia parte do projeto de controle do movimento operário. 
Ao contrário de Miceli, Sartre afirma que o homem é livre para escolher seu próprio destino; ele também diz que a situação pode impedir o pleno exercício de tal liberdade. E, no entanto, Sartre acrescenta, é errado dizer que o meio e a situação determinam, de modo unilateral, o escritor ou o intelectual; o que existe é, sobretudo, um movimento constante para frente e para trás entre eles:

\footnotetext{
Sou um autor, em primeiro lugar, por minha intenção de escrever. Mas imediatamente segue-se que eu me torno homem que outros homens consideram um escritor, isto é, que tem de responder a certa demanda e que foi investido de certa função social. Seja qual for o jogo que ele queira jogar, deve jogá-lo com base na representação que outros fazem dele. Pode querer modificar o caráter que se atribui ao homem de letras numa dada sociedade; mas para mudá-lo tem antes de introduzir-se nela. Depois, o público intervém, com seus costumes, sua visão de mundo e sua concepção da sociedade e da literatura no interior dessa sociedade. O público cerca o escritor, encurrala-o, e suas exigências impiedosas ou dissimuladas, suas recusas e suas fugas são os fatos concretos em cuja base uma obra pode ser construída. (Sartre, 1993, p.77).
}

Lucien Goldman enfatiza que os aspectos biográficos (subjetivos) nem sempre colaboram no entendimento da obra produzida (objetiva), pois esta comporta o conjunto dinâmico das relações sociais, nem sempre conscientes para o seu próprio criador. "Disso resulta que determinados livros não representam a posição de classe a que pertence seu criador, mas, sim, sua adesão a uma determinada "visão de mundo", conceito fundamental nos estudos de Lukács". (Janotti, 2000: p.120). Michael de Certeau diz que "a inteligibilidade da obra do historiador inclui antecedentes referenciais que o discurso não menciona, em função dos quais se instauram métodos, interesses e indagações presentes na leitura e interpretação dos documentos". (Janotti, 2000, p.121).

Daniel Pécaut (1990) afirma que a própria organização dos intelectuais está constantemente articulada ao Estado. No Estado Novo, por exemplo, as profissões foram reconhecidas e receberam um estatuto oficial, o que levou Pécaut a acreditar que a geração de intelectuais dos anos 20-45 agia por "interesse", pois buscavam reconhecimento (status). Essa geração não solicitou a "mão protetora do Estado; ao contrário, mostrou-se disposta a auxiliá-lo na construção da sociedade em bases racionais". Participando das funções 
públicas ou não, manteve uma linguagem que é a do poder. Proclamou a sua "vocação para elite dirigente porque conseguia, melhor do que qualquer outra elite, captar e interpretar os sinais que demonstravam que já existia uma nação inscrita na realidade, mesmo que ainda desprovida de expressão cultural e política”. (Pécault, 1990, p.38). A legitimidade do intelectual provinha da complementaridade entre os três saberes que apresentava: o relativo à dinâmica das massas cegas, o concernente à formação da cultura e o que tratava da organização do político. Os saberes social, cultural e político conferiam a qualificação para o acesso à posição de elite dirigente.

Pécaut afirma que os intelectuais, segundo suas ideologias, podiam ser elite quando necessário, ou povo quando conveniente. Isso ocorre, segundo o autor, devido ao posicionamento dos intelectuais, classe situada entre o povo e o Estado, que também podem estar a favor do governo, ou contra ele.

Pécaut observa, em diversas declarações, que, entre o ofício de intelectual e o de governante, existe uma profunda semelhança. Nestas declarações, aparece a preocupação dos intelectuais em defender sua classe e tomar para si a responsabilidade de dirigir as massas, já que elas não estão prontas para se autogovernar. Assim, é também uma forma de declararem sua candidatura a postos de direção política, confirmada pelo estatuto de fundação da Ação Integralista Brasileira (AIB), fundada em 1932, que menciona a necessidade de uma "participação direta dos intelectuais no governo da República".

Neste período, o que se observa é a preocupação dos intelectuais quanto à "realidade nacional", à "construção da nação", à "organização da nação", ao "realismo". Neste ponto, os chamados "autoritários" têm lugar de destaque: "Os intelectuais e teóricos do regime de 1930 concordavam em querer uma política que não deixasse lugar algum à arbitrariedade dos interesses e paixões democráticas". (Pécault, 1990, p.22). Essa "ideologia de Estado" ${ }^{9}$ opõe-se aos mecanismos de "mercado" e a auto-regulação social. Segundo Pécaut, os motivos que levaram grande parte dos intelectuais a aderirem a uma "ideologia de Estado", foram:

${ }^{9}$ Segundo Lamounier (1987). 


\begin{abstract}
Desconfiança em relação ao funcionamento do capitalismo da época ou condenação por princípios de sua lógica; dúvida sobre a viabilidade do liberalismo político no Brasil ou antipatia doutrinária em relação às próprias premissas do liberalismo; temor inspirado pela multiplicação anárquica de interesses particulares ou pessimismo devido à desorganização do social. (Pécault, 1990, p.55).
\end{abstract}

Daí o sucesso que os intelectuais autoritários despertaram em uma parte de nossa elite dirigente nos anos próximos à Revolução de 30, que, convicta do fracasso de uma democracia, se inspirou nesses intelectuais que, além da base teórica do governo Vargas, também teriam participação no governo.

No Integralismo, os intelectuais (em sua maioria católicos) de todos os escalões, da direção à base, chegaram a formar uma boa parte de seus adeptos, sendo que seus discursos se dirigiam às classes médias. Pécaut assinala que o "Integralismo" não é o mesmo que "totalitarismo". Pécault, citando Miguel Reale, define Estado integral como aquele que exprime o fato de "que entre o Estado e o indivíduo se verifica uma cessão recíproca de faculdades em prol à realização de fins éticos comuns" e que "o todo não deve absorver as partes (totalitarismo), mas integrar os valores comuns, respeitando os valores comuns, respeitando os valores específicos e exclusivos (Integralismo)". (Pécault, 1990, p.67). Pregavam um corporativismo e um Estado fortes, tendendo para um autoritarismo desmobilizador. Paralelamente à ascensão do movimento Integralista, o getulismo ganhava força e cada vez mais adeptos, até que, em 1937, com o Estado Novo, tal movimento se enfraquece por diversas razões.

A Aliança Nacional Libertadora (ANL), fundada em março de 1935 sob a égide do PCB, atraiu também vários intelectuais e membros das classes médias. Proclamou uma aliança aberta a todos os antifascistas e organizou a insurreição armada à maneira tenentista, abrindo também um largo espaço aos militares da reserva e da ativa. Em 1944, permitiu uma aproximação com o getulismo: a ruptura com as origens anarquistas e operárias, rejeição do liberalismo, a insistência nacionalista, adesão ao Estado como agente de transformação. 
Embora tenhamos dito que este período foi marcado pela polarização entre intelectuais autoritários e intelectuais democráticos, muitos não se posicionaram nem de um lado nem de outro. Dentre os liberais, havia aqueles que, em nome do anticomunismo, admitiram apoiar o endurecimento do regime. Pécaut cita Armando Sales de Oliveira, que afirma, em 1936, em nome do Partido Constitucionalista, baseado em São Paulo: “A nossa aspiração é uma democracia robusta, dirigida com autoridade, fiscalizada por uma assembléia assídua e vigilante, e apoiada numa forte organização militar" (Pécault, 1990, p.76). Fernando de Azevedo, também citado por Pécaut, exprimindo as posições das elites liberais dentro da Universidade de São Paulo, afirma: "Temos que substituir a democracia liberal e parlamentar por uma democracia mais próxima da democracia direta [democracia real], não somente política, mas político-econômica, com instituições sindicalistas ou corporativistas obrigatórias”. (Pécault, 1990, p.88).

Travando um diálogo com Miceli, Pécaut critica o esboço metodológico baseado no laço estabelecido pelo autor de Intelectuais e a classe dirigente no Brasil entre a posição individual de origem e as estratégias pelas quais recorriam ao Estado. As circunstâncias de serem herdeiros sem herança não basta para explicar por que esses intelectuais se sentiam investidos de uma missão política. Em um texto publicado em $1990^{10}$, Miceli rechaça tais críticas e aponta para a ausência de conceituação da cultura política: a posição social dos intelectuais. Assim, Miceli acusa Pécaut de realizar uma "história das idéias, em que as opiniões dos autores são tomadas pelo seu valor de face, pelo sentido literal, como indícios de verdade de sua posição e de seu projeto social". (Miceli, 2001, p.378).

Vimos que o grande debate nos anos 30 se travou em torno da relação Estado e sociedade e da relação entre os intelectuais e o poder. Como é fato, muitos intelectuais aceitaram participar do governo Vargas. É lógico supor que essa escolha, longe de ser a única opção, configurou aceitação dos limites, possibilidades e riscos a que essa atitude poderia levar.

Até que ponto essa decisão afetou a independência intelectual? Pécaut (1990) questiona se devido a este vínculo com o Estado serão os intelectuais

${ }^{10}$ Miceli (2001). 
capazes de militar a favor da democracia? Para que isso ocorra, é preciso que os intelectuais não se contentem em intervir politicamente, mas reconheçam a dimensão própria ao plano político. Encontramos tipos muito diversificados de relação entre os intelectuais e o regime. Alguns se comportam como ideólogos do autoritarismo, ocupam funções no Estado, colocam seu talento literário ou artístico diretamente a serviço da política oficial. Outros se contentam em aventurar-se por conta própria em busca do Brasil autêntico, lutar para impor temas nacionais, inventar modos brasileiros de expressão e, havendo oportunidade, apresentar sugestões e pedidos aos governantes e ao seu círculo. Outros, porém, engajam-se resolutamente nas associações, movimentos e ligas que proliferam após 1930.

Carlos Drummond de Andrade, por exemplo, foi chefe de Gabinete de Gustavo Capanema e simpatizante do Partido Comunista, sem ao menos se "vender" àquela ideologia de Estado. Como realça Antonio Candido ${ }^{11}$ :

\footnotetext{
Carlos Drummond de Andrade 'serviu' o Estado Novo como funcionário que já era antes dele, mas não alienou por isso a menor parcela de sua dignidade ou autonomia mental. Tanto assim que as suas idéias contrárias eram patentes e foi como membro do Gabinete do ministro Capanema que publicou os versos políticos revolucionários de Sentimento do mundo e compôs os de Rosa do povo. (Miceli, 1979, p.74).
}

Do mesmo modo, Pécaut (1990, p.72) diz: “É, portanto, reconhecido, tanto pelos contemporâneos como pelos historiadores, que o regime de Getúlio Vargas, até mesmo durante o Estado Novo, preservou para os intelectuais, e para os que estavam a seu serviço, uma ampla liberdade de criação".

Estamos convencidos que o fato de Sérgio Buarque de Holanda ter aceitado cargos públicos deu-se exatamente por essa "liberdade" concedida por parte do Estado. A independência intelectual de Sérgio Buarque de Holanda sobreviveu mesmo tendo sido participante ativo do funcionalismo público, que, aliás, é a trajetória intelectual de quase a totalidade dos intelectuais desse período, e por que não dizer da própria história da intelectualidade brasileira.

${ }^{11}$ No prefácio de Miceli (1979). 
Outro traço que marca a história intelectual brasileira, é a forma como os intelectuais ingressaram nas carreiras públicas: por meio da "rede de relações". No Brasil, a indicação, o sobrenome, a filiação partidária sempre facilitaram a admissão do postulante a qualquer cargo público. Mérito e competência, definitivamente, não são as características principais para o ingresso no setor público. Esse tema, já discutido em Raízes do Brasil, revela um traço importante de nossa cultura: o personalismo e o bacharelismo.

Não obstante, verificamos que, na trajetória intelectual de Sérgio Buarque de Holanda, encontra-se também a rede de relações. Afonso de Taunay, sem dúvida, foi aquele que mais esteve presente na vida de Sérgio. Foi seu professor no Colégio São Bento, indicando seu primeiro artigo, "Originalidade literária", para publicação. Considerado por Sérgio o "maior historiador brasileiro", foram amigos durante toda a vida. Sérgio Buarque de Holanda o substituiu no Museu Paulista e ocupou sua cadeira na Academia Paulista de Letras.

Na Faculdade de Direito da Universidade do Distrito Federal, no Rio de Janeiro, Sérgio conhece Prudente de Moraes, neto, e Afonso Arinos de Melo Franco, amigos para o resto da vida: "Sérgio jamais foi um estudante assíduo nem interessado”, revelava Maria Amélia ${ }^{12}$, sua esposa. Mas foi nesse momento que Sérgio, juntamente com Prudente de Morais, neto, em meio aos livros da livraria Garnier, onde pesquisavam toda literatura inspiradora do movimento modernista, resolveu fundar uma revista, Estética, nome batizado por Graça Aranha, padrinho dessa idéia. Depois, Sérgio Buarque de Holanda torna-se representante da revista modernista Klaxon.

A rede de relações pela qual Sérgio percorria levou-o a trabalhar em diversos órgãos públicos, sempre por indicação de um amigo. As indicações revelam dois traços marcantes do historiador: o seu carisma e a sua competência. Essa “rede de relações”, estudada por Miceli (2001), revela que a ascensão social dessa geração deu-se por se valerem do capital de relações sociais, em especial em conjunturas estratégicas, como a educação dos filhos, a "escolha" dos cursos superiores, o casamento, a nomeação para cargos

\footnotetext{
${ }^{12}$ Em uma biografia chamada "Apontamentos para a cronologia de Sérgio", publicado no site
} www. unicamp.br/sbh, em 2002. 
públicos, etc. Nesse sentido, a trajetória de Sérgio Buarque de Holanda não difere de outros intelectuais de sua geração. O que difere Sérgio Buarque de Holanda de sua geração, a meu ver, é a gestão eficiente e competente à frente de tais cargos.

Além disso, essa rede de relações possibilitou o acesso de Sérgio Buarque de Holanda a determinados cargos públicos na esfera tanto federal quanto estadual. O período entre 1930 e 1945, segundo dados apresentados por Miceli (2001), foi marcado por ampla formação de um aparato burocrático estatal, configurado pela "construção institucional" que determinou a abertura de ministérios, secretarias, departamentos, conselhos e de uma rede de autarquias e de comissões especiais que, com efeito, possibilitou a ampliação das vagas para o serviço público, seja por meio direto, seja por meio da relação entre o estado-maior executivo e os diversos setores econômicos.

Assim, Sérgio Buarque de Holanda torna-se diretor da Seção de Publicações do Instituto Nacional do Livro (INL), criado e dirigido por Augusto Meyer, amigo e confrade dos modernistas. Nomeado em 05 de junho de 1939, permanece até agosto de 1944. Lá, planejou e dirigiu inúmeras publicações, destacando-se a Biblioteca Popular Brasileira, com cerca de 50 volumes, entre história, literatura e diários de viagem, como o de Lacerda e Almeida, e antologia da poesia colonial brasileira, as poesias de José Bonifácio (o velho), a exposição sobre a vida e obra do mesmo José Bonifácio.

Em 1944, inicia seu trabalho na Biblioteca Nacional, na Divisão de Consulta, assessorando primeiramente Rodolpho Garcia e depois Rubens Borba de Moraes. Foi diretor até 5 de fevereiro de 1946. No tempo em que esteve à frente da Divisão de Consulta da Biblioteca Nacional, Holanda lecionou, em 1945, a disciplina História do Brasil para alunos do curso de Biblioteconomia. Miceli (2001) distingue uma série de cargos ocupados por intelectuais na esfera pública, dentre os quais a de "administradores da cultura e cia." Nesse universo, encontra-se Sérgio Buarque de Holanda, no cargo de Diretor de Consulta da Biblioteca Nacional. Para esse cargo, era necessário saber especializado e "incluem-se, entretanto, intelectuais cuja posição funcional é radicalmente distinta tanto do ponto de vista do trabalho que desenvolvem como no que se refere à sua proximidade dos centros de poder". 
Entendemos que todo cargo público é de natureza política. No entanto, os cargos exercidos por Sérgio ao longo de sua vida foram de natureza técnica (além de política), fato que não o difere na história dos intelectuais brasileiros e que faz parte da cultura presente na gestão pública no Brasil. O que difere Sérgio Buarque de Holanda, como já dissemos, é a gestão eficiente à frente desses cargos.

\section{Os anos 1940 e 1950 e a profissão de historiador}

Depois de muitos anos morando no Rio de Janeiro, retorna a São Paulo em 25 de janeiro de 1946, onde foi nomeado por José Carlos de Macedo Soares, Interventor Federal em São Paulo, para o cargo de historiógrafo do Museu Paulista ${ }^{13}$.

Sérgio Buarque de Holanda definia-se como historiador: "Ao menos por inclinação intelectual e também por profissão". (Holanda, 1987e). E revela: "No meu caso particular, a simples orientação para os estudos históricos só podia reforçar minhas antigas relações com Taunay". (Holanda, 1962, p.78). Sérgio Buarque de Holanda considerava a História o "elo primordial das ciências humanas". (Dias, 1979).

Sérgio Buarque de Holanda revela que foi em Berlim o despertar para os estudos históricos:

\footnotetext{
Descobri um livro interessante - ainda tenho vários livros daquele tempo -, um livro do Kant sobre Frederico III. Eu me lembrava que o Nietzsche dizia para ele o grande Frederico era o II, por isso fiquei intrigado e comprei. Não só o primeiro volume - mais tarde, nos Estados Unidos, encontrei o segundo volume num sebo e consegui comprar. $O$ fato é que daí me veio a idéia para esses assuntos históricos, para uma abordagem maior. Eu sempre tive certa curiosidade por isso. (Holanda, 2004, p.7).
}

Como dissemos anteriormente, Sérgio Buarque de Holanda não teve uma formação acadêmica em História. Ao escrever as críticas literárias nos diversos jornais, percebe-se certa veia historiográfica, configurada pelo cuidado em contextualizar a obra e o autor, além da rica fundamentação baseada em fontes primárias, muitas delas inéditas. Mas foi a partir de seu ingresso no Museu Paulista que ele pôde dedicar-se plenamente aos estudos históricos.

13 Conforme Certidão n. 30/62, expedida pelo Museu Paulista em 5 de dezembro de 1962. (Prontuário SBH/USP). 
Digo plenamente, pois o interesse pelos estudos históricos vem de sua estada na Alemanha, quando escreveu dois textos que viraram a base do livro Raízes do Brasil. Na volta para o Brasil, quando trabalhou na Universidade do Distrito Federal onde foi assistente de Henri Hauser, "um dos mais notáveis historiadores de seu tempo" (Holanda 1979, p.14), Sérgio Buarque de Holanda pôde entrar em contato com a pesquisa e com o rigor científico, ensinamentos transmitidos a ele por meio desses historiadores franceses que trabalharam na então Universidade do Distrito Federal.

O papel do historiador foi discutido por Sérgio Buarque de Holanda no artigo "Erudição e imaginação", quando ele destaca a importância da imaginação tanto para o historiador quanto para o poeta:

Bem sabemos que os fatos nunca falam por si, que o verdadeiro historiador não é apenas o que conseguiu acumulá-los no maior número possível, mas o que soube formular-lhes - a esses fatos as perguntas realmente decisivas, dando-lhes ao mesmo tempo voz articulada e coerência plausível. (Holanda, 1996, p.234).

O historiador no Brasil, e talvez a intelectualidade como um todo, "nunca chegou, salvo casos isolados e em verdade excepcionais, a absorver a lição de curiosidade, de paciência, de rigor, de zelo crítico, que ensinavam alguns velhos mestres, cumpre ainda menos desdenhá-la ante o apelo de virtudes mais insignes e menos humildes". (Holanda, 1996, p.235). A crítica à falta de aprofundamento do historiador brasileiro é amparada pela observação de "ilustre pesquisador norte-americano" que dizia que esses historiadores são, "na sua totalidade, homens incompletos", pois a imaginação e a pesquisa documental são elementos que não pertencem a uma mesma pessoa. Embora Sérgio Buarque de Holanda dê razão a essa observação, um pouco pesada, mas qualificada, ele pondera, dizendo que o material documental de que dispõem os historiadores brasileiros, ainda é pobre e pouco acessível, e a imaginação ainda é mal-educada.

As décadas de 1940 e 1950 são marcadas por uma criatividade cultural que não encontrou paralelo na história da cidade de São Paulo: Fundação do Museu de Arte de São Paulo (1947), MAM (1948), Vera Cruz (1948), TBC (1948), Bienal (1951). Momento em que se reformula a linguagem teatral, cinematográfica e científica. Houve uma ruptura com a sociedade provinciana e conservadora que expelia de seu seio tanto as manifestações eruditas (vistas 
com signo de ostentação de uma burguesia oligárquica) como as de caráter vanguardistas (Teatro de Arena). Engajar-se, nesta época, significava deixar-se envolver pelo clima de efervescência que acabava penetrando no próprio trabalho intelectual. (Barbato Jr, 2004). Talvez esse "clima" tenha favorecido o retorno de Sérgio Buarque de Holanda à sua terra natal, pois ele sempre esteve próximo das vanguardas e das transformações culturais.

Em 9 de fevereiro de 1950, foi promovido ao cargo de Diretor do Museu Paulista, cargo que ocupou até 30 de dezembro $1958^{14}$, quando ingressou, por concurso, na USP. A indicação partiu de Afonso Taunay, que acabara de aposentar-se neste mesmo cargo. No Museu Paulista, cria as seções de História, de Etnologia, de Numismática e de Lingüística. Em seu regresso a São Paulo Sérgio Buarque de Holanda confessa-se feliz: "São Paulo tornara-se inseparável de minha nostalgia da infância e da mocidade. Não exagero em dizer que essa razão íntima, imaterial, foi o que me seduziu na lembrança”." (Holanda, 1962, p.74).

João Ricardo de Castro Caldeira (2005) destaca a ênfase às pesquisas etnológicas dada por Sérgio e por seu colaborador Herbert Bauldus, frente ao Museu Paulista. Caldeira diz também que a principal publicação do museu, intitulada Revista do Museu Paulista, teve novos rumos, a partir da direção do historiador, sobretudo através de teses defendidas na USP: “Ao proceder desse modo, Sérgio Buarque transformou aquele periódico num dos principais veículos de divulgação da produção acadêmica brasileira, antecipando-se ao surgimento de uma imprensa universitária no Brasil”. (Caldeira, 2005, p.65).

No período em que esteve à frente do Museu Paulista, Sérgio Buarque de Holanda pôde participar de diversos eventos científicos no exterior. Em 14 de março de 1949, pede afastamento ${ }^{15}$ para realizar uma viagem de estudo na École Pratique dês Hautes Études, na Sorbonne, e no Musée de L’Homme, em Paris. Em 16 de outubro de 1950, pede outro afastamento ${ }^{16}$ para participar, em Washington, do Colóquio Luso-Brasileiro, retornando em 4 de novembro do

\footnotetext{
14 Conforme Documento n. 380 do Museu Paulista, assinado por Herbert Baldus, responsável pela Diretoria do Museu. (Prontuário SBH/USP).

15 Conforme Certidão n. 30/62, expedida pelo Museu Paulista em 5 de dezembro de 1962 e DO de 20-3-49. (Prontuário SBH/USP).

16 Conforme Certidão n. 30/62, expedida pelo Museu Paulista em 5 de dezembro de 1962 (Prontuário SBH/USP).
} 
mesmo ano. Entre $1^{\circ}$ de janeiro de 1953 e 31 de dezembro de 1954, requer outro afastamento ${ }^{17}$, sem prejuízo de vencimentos, a fim de encarregar-se, na Universidade de Roma, do Curso de Estudos Brasileiros.

A partir de 4 de dezembro de 1956, Sérgio afasta-se por setecentos e quarenta dias do Museu Paulista a fim de lecionar, como professor interino, na Cadeira de História da Civilização Brasileira, na Faculdade de Filosofia, Ciências e Letras, da USP, já que o horário das aulas chocava com o horário do Museu.

José Sebastião Witter (2002), em uma entrevista sobre Sérgio Buarque de Holanda, fez um balanço de sua direção no Museu Paulista, relatando a presença marcante do historiador no museu, configurada pela nova vocação desta instituição para a pesquisa. Embora importante, e até certo ponto prazerosa, Sérgio Buarque de Holanda revela em uma entrevista dada ao Museu da Imagem e do Som (MIS), que o seu trabalho no Museu Paulista era muito burocrático: "Minha letra ficou diferente de tanto assinar papel. E era um problema sempre que alguma coisa quebrava. O dinheiro chegava em junho, e quando vinha janeiro já tinha acabado. Tínhamos que pagar do próprio bolso". (Holanda, 2004, p.12). De fato, o historiador não gostava de atividades burocráticas, que tomavam muito tempo e não revertiam em produtividade intelectual.

\section{Conclusão}

A relação entre intelectuais e Estado, presente nos anos 30 e 40, levounos a repensar até que ponto a independência podia ser sustentada num período de extremo autoritarismo? Em toda sua trajetória profissional, Sérgio Buarque de Holanda manteve uma forte rede de relações que facilitou a obtenção de cargos públicos. Entendemos que a cooptação dos intelectuais pelo Estado vai muito além da simples “ideologia de Estado", pois serviu para aparelhar esse moderno Estado burocrático que se constituía e, com efeito, necessitava de profissionais que prestassem serviços de qualidade. No caso de Sérgio Buarque de Holanda, os cargos públicos ocupados foram todos de

${ }^{17}$ Conforme Certidão n. 30/62, expedida pelo Museu Paulista em 5 de dezembro de 1962 e DO de 21-12-52. (Prontuário SBH/USP). 
caráter técnico, o que exigia formação acadêmica e competência. É fato que a rede de relações facilitou esse ingresso, mas a sua atuação à frente desses cargos revelou a seriedade e o compromisso com a coisa pública, atitudes típicas de um intelectual independente, que não se deixou contaminar pela ideologia do Estado.

O encontro com a História marca definitivamente o amadurecimento do escritor. Como foi dito, seus textos, seja de juventude, seja de crítica literária, sempre foram marcados pela análise e contextualização histórica. Ao regressar da Alemanha, no início dos anos 30, Sérgio Buarque de Holanda abraça definitivamente a profissão de historiador, construída ao longo da publicação de alguns textos, tais como Raízes do Brasil, Monções, Primórdios da expansão paulista em fins do século XVI e princípio do século XVII, Índios e mamelucos na expansão paulista e Caminhos e Fronteiras, além de dezenas de artigos publicados em diversos jornais e revistas. O ingresso no Museu Paulista, em 1946, permitiu ao historiador realizar diversas atividades, tais como: reorganizar esse importante museu, reordenar a publicação dos Anais (revista especializada na área), participar de diversos eventos, entre outros. Com certeza, a atuação à frente do Museu foi uma realização e solidificou a sua escolha pela história, mesmo desgostando do trabalho burocrático.

O recorte realizado foi do início dos anos 20 até o fim dos anos 50, que culminou mais especificamente no ano de 1956, data de seu ingresso na USP como professor substituto. Concomitantemente às atividades na Universidade de São Paulo, Sérgio Buarque de Holanda dirigiu o Museu Paulista e ministrou aulas na Escola Livre de Sociologia e Política. Essa fase de transição durou dois anos. Em 1958, assumiu a cátedra de História da Civilização Brasileira, na USP. Este é o momento de completude de um dos maiores historiadores brasileiros.

\section{Referências bibliográficas}

AVELINO FILHO, George. (1987), “As raízes de Raízes do Brasil”. Novos Estudos CEBRAP, São Paulo, n.18, set.

BARBADO JR, Roberto. (2004), “Os intelectuais, a política e o Departamento de Cultura de São Paulo”. Revista Trapézio, Campinas, n.3/4, $1^{\circ}$ sem. 
BARBOSA, Francisco de Assis (Org.). (1989), Raízes de Sérgio Buarque de Holanda. Rio de Janeiro, Rocco.

BARBOSA, Francisco de Assis. (1988), "Verdes anos de Sérgio Buarque de Holanda: ensaio sobre sua formação intelectual até Raízes do Brasil". In: . Sérgio Buarque de Holanda vida e obra. São Paulo, Secretaria de Estado da Cultura/IEB-USP.

CANDIDO, Antônio. (1989), "A Revolução de 30 e a Cultura". In: - A Educação pela noite \&o outros ensaios. São Paulo, Ática.

DIAS, Maria Odila Leite Silva (Org.). (1985), Sérgio Buarque de Holanda historiador. In: Sérgio Buarque de Holanda. São Paulo, Ática. (Coleção Grandes Cientistas Sociais, 51).

EULÁLIO, Alexandre. (1993), "Sérgio Buarque de Holanda - Escritor". In: HOLANDA, S B. Raízes do Brasil. Rio de Janeiro, José Olympio.

GRAHAM, Richard. (1987), "Uma entrevista". Revista do Brasil, Rio de Janeiro, v.3, n.6.

HOLANDA, S.B. (1996), O Espírito e a Letra I e II. São Paulo, Cia. das Letras. (1979), Tentativas de mitologias. São Paulo, Perspectiva.

(1962), "Discurso do Sr. Sérgio Buarque de Holanda". Revista da Academia Paulista de Letras, São Paulo, v.22, n.67, jul.

(2004), "Corpo e alma do Brasil - entrevista de Sérgio Buarque de Holanda". Novos Estudos CEBRAP, n. 69, p. 03- 14.

JANOTTI, M.L.M. (2000), “O diálogo convergente: políticos e historiadores no início da república”. In: FREITAS, Marcos César de. Historiografia brasileira em perspectiva. São Paulo, Contexto.

LAMOUNIER, Bolívar. (1977), "Formação de um pensamento político autoritário na primeira República : uma interpretação". In: FAUSTO, Boris (Org. ). O Brasil Republicano. Rio de Janeiro, Difel, Tomo III. (Coleção História Geral da Civilização Brasileira, 2).

LEONEL, Maria Célia. (1984), Estética Revista Trimestral e Modernismo. São Paulo, Hucitec.

MICELI, Sérgio. (2001), Intelectuais à brasileira. São Paulo, Cia. das Letras.

MICELI, Sérgio. (1979), Intelectuais e a classe dirigente no Brasil. São Paulo, Difel.

NEMI, Ana Lúcia Lana. (2003), "Os intelectuais nos anos 20: caminhos e ambigüidades”. Campinas, Trapério, n. 3/4. 
PÉCAUT, Daniel. (1990), Os intelectuais e a política no Brasil. São Paulo, Ática.

PRADO, Antônio Arnoni. (1998), "Raízes do Brasil e o modernismo". In: Sérgio Buarque de Holanda e o Brasil. São Paulo, Fundação Perseu Abramo.

SARTRE, Jean-Paul. (1993), Que é a literatura? São Paulo, Ática.

SILVA, Helenice Rodrigues. (2002), Fragmentos da bistória intelectual - entre questionamentos e perspectivas. Campinas, Papirus.

WITTER, José Sebastião. (2002), "Sérgio Buarque de Holanda 1902 - 2002”. Notícia Bibliográfica e Histórica, Campinas, n. 187, out-dez, p. 297-306. 